\title{
ESTIMATING OF EVAPOTRANSPIRATION USING ARTIFICIAL NEURAL NETWORK
}

\author{
Genaidy, M. A.*
}

\section{ABSTRACT}

This study investigates the application of artificial neural networks (ANNs) on the prediction of daily grass reference crop evapotranspiration (ET) and compares the performance of ANNs with the conventional method (Penman-Monteith). The use of ANNs was examined number of hidden layers and the activation function were also tested. The best ANN architecture for estimation of daily ET 0 was obtained for different data set for Nubaria. Using these data, the networks were trained with daily climatic data (maximum and minimum temperature, dew point and wind speed) as input and the Penman-Monteith (PM) estimated ET 0 as output. The analysis was carried out with MATLAB software. Feed forward onelayer networks with sigmoid function were used. Performance evaluation of the models have been carried out by calculating root mean square error (RMSE), The network were selected based on maximized $R$ and $R^{2}$ value and minimized RMSE values which were 0.98, 0.957 and $0.44 \mathrm{~mm} /$ day, respectively in testing. The optimal ANN (4-12-1) for Nubaria regions showed a satisfactory performance in the ETo estimation. These ANN models may therefore be adopted for estimating ETo in the study area with reasonable degree of accuracy.

Keywords: Reference Evapotranspiration; Penman-Monteith Method; Artificial Neural Network; Back- propagation Algorithm; Training; Testing.

\section{INTRODUCTION}

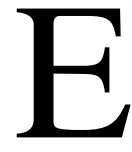
vapotranspiration (ET) is an important component of the hydrologic cycle, and its accurate predictions is of paramount importance for many investigations such as irrigation system design and management, hydrologic water balance, crop yield simulation, irrigation scheduling, drainage studies, agricultural and forest meteorology, and water resources planning and management (Banihabib et al.,2012; Kumar et al.,2002 and Ahmed et al.,2005).

*Agric. Eng. Dept., Fac. of Agric., Ain Shams Univ. 
Evaporation pans are widely throughout the world to estimate $\mathrm{ET}_{\mathrm{o}}$. Evaporation pan (Ep) requires a measurement of the collective influence of temperature, humidity, wind speed and solar radiation on the reference crop evapotranspiration. This measurement can positively be used estimate $\mathrm{ET}_{0}$ with a logical accuracy (Irmak et al. ,2003). Evaporation is a function of temperature, wind speed and humidity, all of which are conditional. Wind revolutions the humidity and if the humidity is low, the evaporation rate is higher. At the same time, air temperature effects humidity and surface temperature. All these influences provide to evaporation with temperature likely being the foremost factor influencing evaporation. Because of maximum and minimum air temperature can be simply recorded at most weather stations world-wide, the PM method is the standard technique when there is no measured lysimeter data (Utset et al.,2004; Gavilan et al.,2006). The study confirmed the superior performance of the PM method in all climatic conditions. Similar comparative studies (Allen et al.,2000; Hargreaves and Allen, 2003; Itenfisu et al.,2003; Temesgen et al.,2005; Nandagiri and Kovoor, 2006; Lopez-Urrea et al.,2006) ) implemented after the evolution of FAO-56 PM method (Allen et al.,1998) recognized FAO-56 PM as the global standard $\mathrm{ET}_{\mathrm{o}}$ estimation method. Although, further research is needed on irrigation management to find the suitable model to be applied for estimating crop evapotranspiration (ET), to prevent the excess or deficit water application, waterlogging, and soil salinity (Eslamian et al.,2009). Effective software tools in the domains specified above require the estimation of $\mathrm{ET}_{0}$ and the processes to act that have been frequently applied in software applications. This is some of the causes that why there is an improving requirement for flexible methods in model improvement (Jones et al.,2001). Reference evapotranspiration can be evaluated by lysimeters; while, this method is extremely costly and not easy to usage (Valipour 2014). Several researchers have evaluated to estimate the evaporation throughout the direct models using the weather parameters; however, some of these methods require the data, which cannot easily be determined (Rosenberry et al.,2007). A method that can be used for this objective is the artificial neural network (ANN). ANN are active tools to model nonlinear systems and require less inputs. Consistent with Sudheer et al. (2003), ), the most important advantage of ANN methods on 
conventional methods is the ability for solving problems which are complex to formalize The ANN model having only three inputs, the $\mathrm{T}_{\max }$ and $\mathrm{T}_{\min }\left({ }^{0} \mathrm{C}\right)$ and $\mathrm{Ep}\left(\mathrm{mm} \mathrm{d}^{-1}\right)$ were used to demonstrated that modeling of daily $\mathrm{ET}_{\mathrm{o}}$ through the use of ANN method gave better estimates than the conventional methods that require wind speed and humidity data (Jadeja, 2011). Feedforward Backpropagation (BP) algorithm was working to train the MLP neural network. Levenberg-Marquardt (LM) algorithm was utilized with an early stopping cause to improve the network training rate and efficiency. For the standard, all the data were parted into three sets (Coulibaly et al.,2000). Several researchers have used ANN models to estimate evapotranspiration as a function of climatic data (Sudheer et al., 2003; Trajkovic et al.,2003; Trajkovic, 2005; 2007; Keskin and Terzi, 2006; Khoob, 2008; Kim and Kim, 2008; Kisi, 2008; Landeras et al., 2009).This study aims to use an artificial neural network (ANN) to predict the values of the Evapotranspiration $\mathrm{ET}_{0}$ with a specific daily climate data set.

\section{MATERIALS AND METHODS}

Recently, there has been considerable interest in employing ANNs model to a wide variety of environmental processes due to their ability to identify complex input-output relationships. Additionally, ANNs have been used extensively for meteorological applications. In this research, ANNs were used to estimate $\mathrm{ET}_{0}$ based on the minimum air temperature $\left(\mathrm{T}_{\min }\right)$ and maximum air temperature $\left(\mathrm{T}_{\max }\right)$, dew point data (DP) and wind speed (WS). Data of past 17 years (1 January 2000 to 31 December 2016) were collected from standard agricultural meteorological stations of the Agricultural Research Center in the tests station of Nubaria Province, ElBehira Governorate, Egypt, at latitude $30^{\circ} 30^{\backslash} 1.4^{\prime \prime} \mathrm{N}$, and longitude $30^{\circ} 19^{\backslash}$ $10.9^{\|} \mathrm{E}$, and mean altitude $21 \mathrm{~m}$ above sea level. For the calculation of Reference Evapotranspiration $\mathrm{ET}_{0}$ The FAO Penman-Monteith Equation recommended (Allen et al., 1998) which may be written as.

$$
E T_{0}=\frac{0.408 \Delta\left(R_{n}-G\right)+900 \gamma u_{2}\left(e_{s}-e_{a}\right) /(T+273)}{\Delta+\gamma\left(1+0.34 u_{2}\right)}
$$

Where:

$E T_{0}:$ Reference evapotranspiration $\left[\mathrm{mm} \mathrm{day}^{-1}\right]$, 
$R_{n}$ : Net radiation [MJ m-2 day ${ }^{-1}$,

G: Soil heat flux density $\left[\mathrm{MJ} \mathrm{m}^{-2}\right.$ day $\left.^{-1}\right]$,

$\mathrm{T}$ : Mean daily air temperature at $2 \mathrm{~m}$ height $\left[{ }^{\circ} \mathrm{C}\right]$,

$u_{2}$ : Wind speed at $2 \mathrm{~m}$ height $\left[\mathrm{m} \mathrm{s}^{-1}\right]$,

$e_{s}:$ Saturation vapor pressure $[\mathrm{kPa}]$,

$e_{a}:$ Actual vapor pressure $[\mathrm{kPa}]$,

$\mathrm{e}_{\mathrm{s}}-\mathrm{e}_{\mathrm{a}}$ : Saturation vapour pressure deficit $[\mathrm{kPa}]$,

$\Delta$ : Slope of the vapour pressure curve $\left[\mathrm{kPa}^{\circ} \mathrm{C}^{-1}\right]$,

$\gamma$ : Psychrometric constant $\left[\mathrm{kPa}{ }^{\circ} \mathrm{C}^{-1}\right]$.

Daily $\mathrm{ET}_{0}$ values showed in fig. (1) were estimated using the PM method to use in target in ANNs. Among the different types of ANNs, multilayer perceptron (MLP) neural networks are quite popular and were used in this study. MLP consists of an input layer, an output layer, and hidden layers. Several joined giving nodes or neurons are organized in these layers. The neurons in the hidden layers which are connected to the neurons in the previous layer and the following layer by adaptable weights, allow the network to calculate

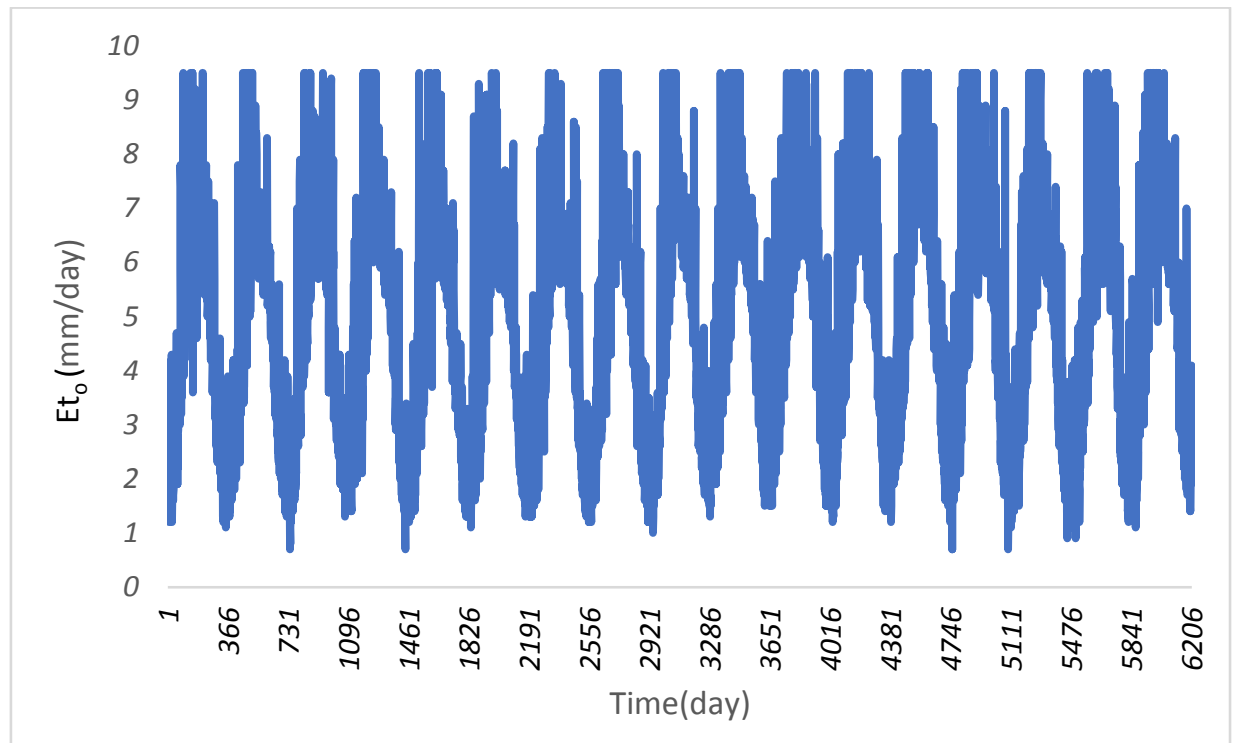

Figure 1: Deviation of daily reference evapotranspiration (January 2000December 2016) from standard agricultural meteorological stations of Nobaria. 
complex links between the inputs and outputs. The procedure of determining these weights is known as training. Essentially, the network is trained to model an input-output relationship during an observed training procedure by operating a cycle of input and linked output data. The number of nodes in the input and the output layers depends on the number of input and output variables, respectively MATLAB (R2016b) that includes an "Artificial Neural Network toolbox" (nnstart) was used to construct, train, and simulate neural networks. A two-layer feed-forward network with sigmoid hidden neurons and linear output neurons, can Fit well multidimensional representing problems Arbitrarily giving consistent data and enough neurons in its hidden layer. The network will be trained with Levenberg-Marquardt back propagation algorithm, in which case scaled conjugate gradient back propagation will be used. In this structure, there are four neurons in the input layer (representing the $T_{\max }, T_{\min }, \mathrm{DP}$ and WS variables), i neurons in a single hidden layer, and one neuron in the output layer (representing the $\mathrm{ET}_{0}$ ). Inside each hidden neuron, a weighted sum of inputs is treated using a transfer function. The transfer function in the networks was sigmoid in this study. Networks with a single hidden sigmoid layer are by far the most frequently used network topology. This is likely because they can guess any function with a finite number of breaks if enough training is performed. All data were divided randomly into three sets. Out of total number of 6209 patterns, 4347 (70\%) had been used for training, 931(15\%) had been used for validation of the network while the remaining 931(15\%) had been used for testing the model. The performance of the ANN depends on the number of nodes in the hidden layer. Because no specific guidelines occur for choosing the optimum number of hidden nodes for a given problem, this network parameter is often optimized using a combination of empirical rules such as trial and error. Fig. 2 shows the general layout of a three-layer neural network used in this study. The training process was repeated for the new architecture. This procedure was continued for several different architectures. Eventually, the ANN architecture that resulted in the high correlation coefficient (R) and less root mean square error (RMSE) over the training epochs was adopted as the optimal ANN architecture. In the present study, the performance of the ANN model is examined for two distinct types of transfer functions of the 
hidden layer namely, the logarithmic sigmoid function (logsig) and hyperbolic (logsig) and hyperbolic tangent sigmoid function (tansig). With the change of the transfer function for the output layer, they become the logarithmic sigmoid function (logsig), hyperbolic tangent sigmoid function (tansig), and linear function (pureline). The number of nodes ranged from 3 to 15 in the hidden layer. Training constitutes the first stage in implementation of a neural network designed to identify the relationship between the independent and dependent variables of a given process. Prior to exporting the data to the ANN for training, the data were normalized. This was done to restrict their range within the interval of $0-1$, because the PEs of the middle layer were assigned a sigmoidal activation function. The shape of this function shows an important role in ANN learning. The weight changes corresponding to a value near 0 or 1 are minimal since PE is ' dull' whereas closer to 0.5 they respond more. Keeping these facts in view, the normalization was approved out so that the mean of the data series would be equal to 0.5 and then revisited to the original values after simulation. The following equation was used:

$$
X_{\text {nom }}=0.5\left(\frac{X_{0}-\bar{X}}{X_{\text {max }}-X_{\text {min }}}\right)+0.5
$$

where:

$X_{\text {nom }}$ :normalized value; $X_{0}$ :original value; $\bar{X}$ :mean; $X_{\text {max }}$ :maximum value; and $X_{\min }$ :minimum value.

The NNS provides information on mean sum of square error MSE during the training and validation. Using the test input data Set, the $\mathrm{ET}_{\mathrm{o}}$ predicted the performance of each network. The data used for the testing of neural network (daily weather data from 931 patterns; 2007-2008) were used for comparison of the selected ANN and the PM method. This comparison was done by using three statistical indices: determination coefficient $\left(\mathrm{R}^{2}\right)$, root mean square error (RMSE) and the ratio between average estimated $\mathrm{ET}_{\mathrm{o}}$ values and observed $\mathrm{ET}_{\mathrm{o}}$ values correlation coefficient $(\mathrm{R})$. The $\mathrm{R}^{2}$ measures the degree to which two variables are linearly related and should optimally be one. These indices defined as follows: 


$$
\begin{gathered}
R^{2}=\frac{\left[\sum\left(\boldsymbol{P}_{i}-P\right)\left(\boldsymbol{O}_{i}-O\right)\right]^{2}}{\sum\left(\boldsymbol{P}_{i-} P\right)^{2} \sum\left(\boldsymbol{O}_{o}-O\right)^{2}} \\
R M S E=\left[N^{-1} \sum_{i=1}^{N}\left(\boldsymbol{P}_{i}-\boldsymbol{O}_{i}\right)^{2}\right]^{0.5} \\
R=P / O
\end{gathered}
$$

Where:

$\mathrm{N}$ is the number of observations, $\mathrm{P}_{\mathrm{i}}$ is the predicted (using the ANN and conventional methods), $\mathrm{O}_{\mathrm{i}}$ is the observed $\mathrm{ET}_{\mathrm{o}}$ (calculated with the PM method), $\mathrm{P}$ and $\mathrm{O}$ are the average value for $\mathrm{P}_{\mathrm{i}}$ and $\mathrm{O}_{\mathrm{i}}$.

\section{RESULTS AND DISSCUSSION}

\section{-Data entry and neural network construction}

The artificial neural network was formed of the input layer consisting of four neurons representing the degree maximum and minimum temperature degree, dew point and wind speed, and the output layer consisting of one array representing the reference evapotranspiration $\left(\mathrm{ET}_{\mathrm{o}}\right)$, and the number of hidden layer neurons which was determined by the experiment, by changing the number of hidden layer neurons with the training algorithm installed and Activation of all sealed networks and training of the network until obtaining the minimum rate of root main square error (RMSR). The neural networks were trained with 3-15 hidden nodes and after each training run; RMSE, $\mathrm{R}^{2}$ and $\mathrm{R}$ were calculated using only the test data set to find the optimal number of hidden nodes. Table (1) shows the effect of changing the number of nodes in hidden layer on the network accuracy. This factor had a significant bearing on the network accuracy.

\section{Training the proposed artificial neural network}

After conducting many experiments, it is possible to find the synthetic neural network with (4-12-1) Fig2. The best RMSE and R $(0.44 \mathrm{~mm} /$ day and 0.98 , respectively) values also were found with twelve nodes. Hence, the network using twelve nodes in the hidden layer was selected for daily $\mathrm{ET}_{\mathrm{o}}$ estimation in this study. The activation function was also tested, in the artificial neural network with (4-12-1).The best performance of the 
artificial neural network was performed using the activation function Transfer function tan sigmoid in the hidden layer and was followed Transfer function tan sigmoid in output layer as shown in Table (2). Fig. (3) shows the performance of the artificial neural network of the three groups with an average error of (0.0007) for the investigation group.

Table (1): RMSE and R values of ANN models with three to fifteen nodes in the hidden layer for computing ETo.

\begin{tabular}{|c|c|c|c|c|c|c|c|c|}
\hline & \multicolumn{2}{|c|}{ Training } & \multicolumn{2}{c|}{ Validation } & \multicolumn{2}{c|}{ Test } & \multicolumn{3}{c|}{ All } \\
\hline $\begin{array}{c}\text { Network } \\
\text { Architecture }\end{array}$ & $\begin{array}{c}\text { RMSE } \\
(\mathrm{mm} / \text { day })\end{array}$ & $\mathrm{R}$ & $\begin{array}{c}\text { RMSE } \\
(\mathrm{mm} / \mathrm{day})\end{array}$ & $\mathrm{R}$ & $\begin{array}{c}\text { RMSE } \\
(\mathrm{mm} / \mathrm{day})\end{array}$ & $\mathrm{R}$ & $\begin{array}{c}\text { RMSE } \\
(\mathrm{mm} / \mathrm{day})\end{array}$ & $\mathrm{R}$ \\
\hline $4-3-1$ & 0.0267 & 0.9762 & 0.0267 & 0.9762 & 0.0268 & 0.9757 & 0.9744 & 0.9744 \\
\hline $4-4-1$ & 0.0264 & 0.9767 & 0.0261 & 0.9772 & 0.0278 & 0.9744 & 0.9764 & 0.9764 \\
\hline $4-5-1$ & 0.0265 & 0.9770 & 0.0261 & 0.9762 & 0.0268 & 0.9754 & 0.9766 & 0.9766 \\
\hline $4-6-1$ & 0.0258 & 0.9779 & 0.0262 & 0.9774 & 0.0258 & 0.9775 & 0.9777 & 0.9777 \\
\hline $4-7-1$ & 0.0254 & 0.9783 & 0.0258 & 0.9782 & 0.0250 & 0.9796 & 0.9786 & 0.9786 \\
\hline $4-8-1$ & 0.0256 & 0.9781 & 0.0265 & 0.9770 & 0.0254 & 0.9787 & 0.9780 & 0.9780 \\
\hline $4-9-1$ & 0.0259 & 0.9772 & 0.0257 & 0.9789 & 0.0258 & 0.9789 & 0.9778 & 0.9778 \\
\hline $4-10-1$ & 0.0252 & 0.9787 & 0.0252 & 0.9795 & 0.0257 & 0.9784 & 0.9788 & 0.9788 \\
\hline $4-11-1$ & 0.0256 & 0.9781 & 0.0254 & 0.9796 & 0.0257 & 0.9774 & 0.9783 & 0.9783 \\
\hline $4-12-1$ & 0.0239 & 0.9795 & 0.0240 & 0.9786 & 0.0248 & 0.9799 & 0.9798 & 0.9798 \\
\hline $4-13-1$ & 0.0249 & 0.9793 & 0.0251 & 0.9821 & 0.0251 & 0.9776 & 0.9796 & 0.9796 \\
\hline $4-14-1$ & 0.0242 & 0.9805 & 0.0260 & 0.9774 & 0.0262 & 0.9772 & 0.9796 & 0.9796 \\
\hline $4-15-1$ & 0.0247 & 0.9797 & 0.0256 & 0.9791 & 0.0260 & 0.9768 & 0.9792 & 0.9792 \\
\hline
\end{tabular}

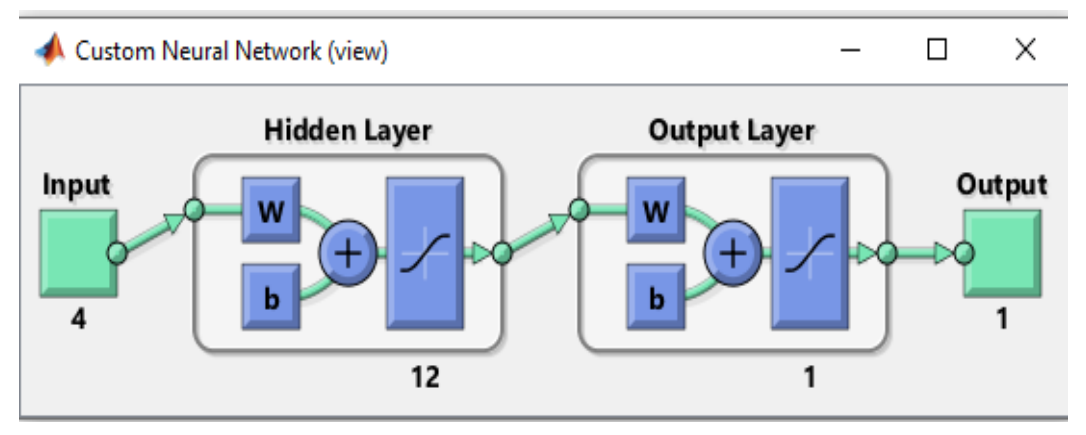

Fig. (2): Neural Network Structure. 
Table (2): The performance of the artificial neural network when using multiple activation functions.

\begin{tabular}{|c|c|c|}
\hline Hidden layer & Output layer & $\begin{array}{c}\text { All } \\
\text { (RMSE) }\end{array}$ \\
\hline Tansig & Purelin & 0.024820 \\
\hline Tansig & Logsig & 0.096464 \\
\hline Tansig & Tansig & 0.024528 \\
\hline Logsig & Purelin & 0.024874 \\
\hline Logsig & Logsig & 0.096525 \\
\hline Logsig & Tansig & 0.026039 \\
\hline
\end{tabular}

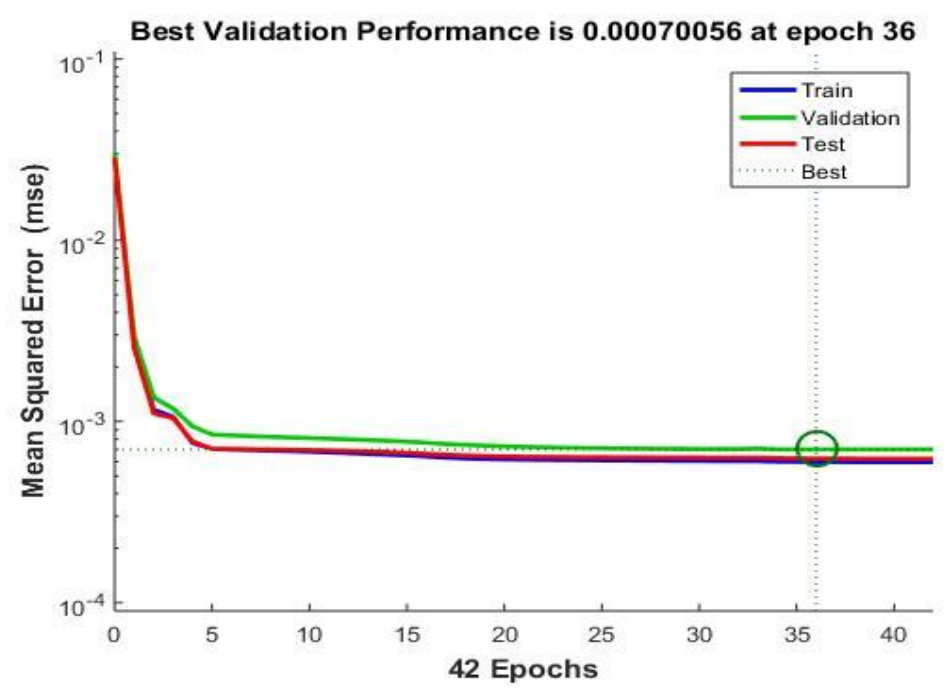

Fig. (3): Mean squared error and the ANN best validation performance.

\section{-Evaluate the performance of the proposed artificial neural network}

Evaluate the performance of the proposed neural network by comparing the results obtained in general from the model for the training, testing and validation group by using curve fitting tool in matlab. $\mathrm{R}$-squared $\left(\mathrm{R}^{2}\right)$ and root mean square error (RMSE) values of developed model in the training, validation period as well as in testing period are given in Fig.4,5 and 6.It can be seen from figures that for ANN model R-squared $\left(\mathrm{R}^{2}\right)$ for training period was 0.9602 , validation period was 0.9597 and for testing period was 0.9575. The value of root mean square error for training period, validation period was $0.42,0.43$ and for testing period it was $0.44 \mathrm{~mm} /$ day after 
standardization response respectively. It is clear from figures that the higher values of correlation coefficients and lower values of root mean square. Error can suggests the applicability of ANN model for evapotranspiration estimation.

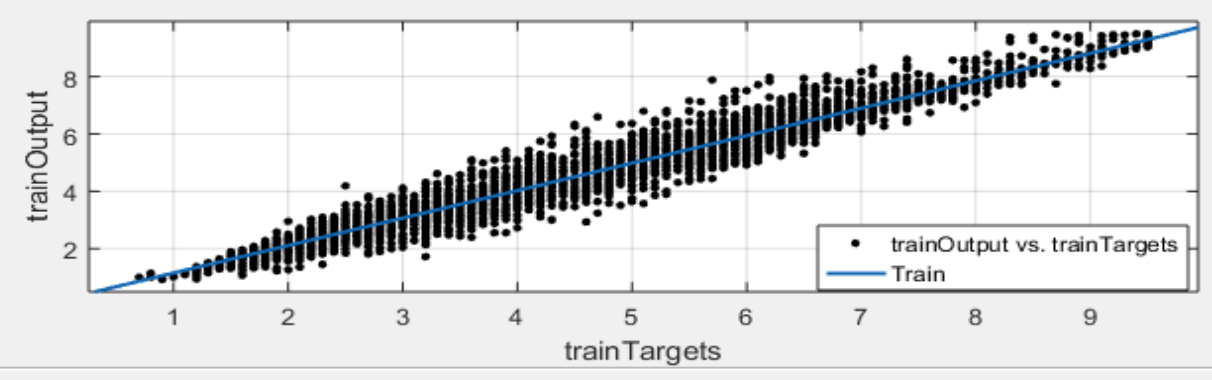

\begin{tabular}{|c|c|c|c|c|c|c|c|c|c|c|c|}
\hline \multicolumn{12}{|l|}{ Table of Fits } \\
\hline Fit name - & Dats & Fis type & SSE & R-square & DFE & Adj R-sq & RMSE & $=$ Coeff & Validation D... & Volidation SSE & Volidation R.. \\
\hline a Train & traino & poly 1 & 773.2608 & 0.9602 & 4345 & 0.9602 & 0.4219 & 2 & & & \\
\hline
\end{tabular}

Fig. (4): The best architecture for the ANN for training data.

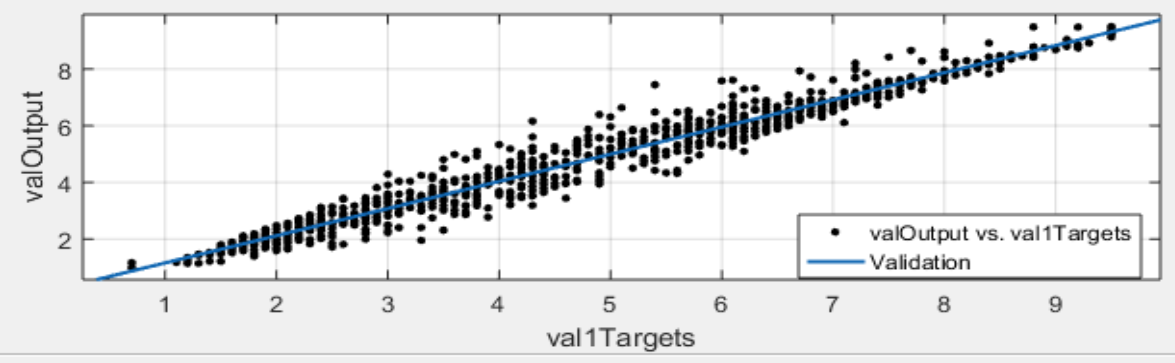

\begin{tabular}{|c|c|c|c|c|c|c|c|c|c|c|c|}
\hline \multicolumn{12}{|l|}{ Table of Fits } \\
\hline Fit name - & Dsts & Fitype & SSE & R-square & OfE & Adj R-sq & RMSE & $=$ Coeff & Validetion D.... & Validation SSE & Volidation $R$... \\
\hline Ia validation & valOut & poly1 & 172.1556 & 0.9597 & 929 & 0.9596 & 10.4305 & 2 & & & \\
\hline
\end{tabular}

Fig. (5): The best architecture for the ANN for validation data.

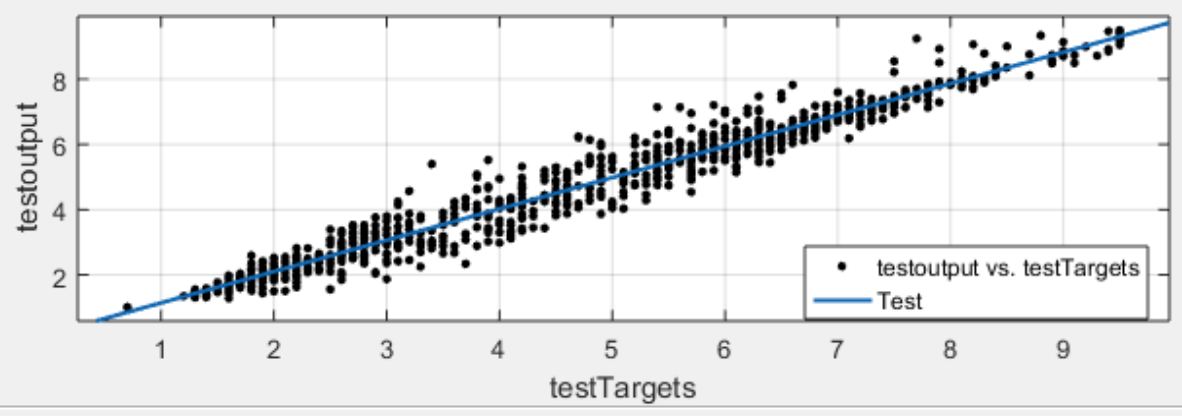

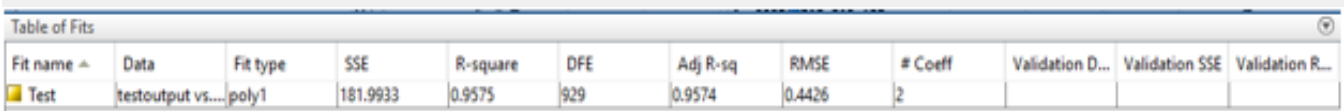

Fig. (6): The best architecture for the ANN for test data. 
Fig. (7) shows the comparison between daily $\mathrm{ET}_{0}$ values estimated by PM method and those prediction by the selected ANN model incorporating all the data points for years under testing of neural network. There was a very strong correlation depicted in the output of the model under discussion. Most of the points lied near the regression line with a few exceptions of greater deviations in the testing mode. However, the correlation above 90 $\%$ encourages this technique to be used in practical applications.

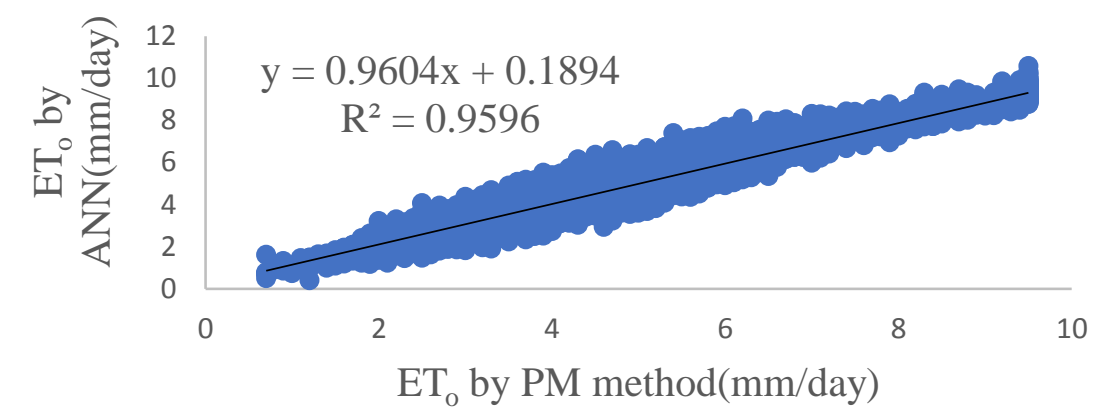

Fig. (7): Relationship between $\mathrm{ET}_{0}$ estimated by $\mathrm{ANN}$ method and $\mathrm{ET}_{0}$ estimated by PM method

\section{CONCLUSIONS}

Evapotranspiration is an important and one of the most difficult components of the hydrologic cycle to be quantified accurately. Prior to designing any irrigation system, the information on crop water requirements or crop evapotranspiration is needed, which can be calculated using reference evapotranspiration. The difficulty in estimating $\mathrm{ET}_{\mathrm{o}}$ with the indirect physically based methods is due to the limitations of unavailability of all necessary climate data. ANNs are efficient in modeling complex processes without formulating any mathematical relationships related to the physical process. This study was undertaken to develop ANN models corresponding to PM conventional $\mathrm{ET}_{\mathrm{o}}$ method for station of Nubaria Province. The ANN model was developed considering four inputs ( $\mathrm{T}_{\max }, \mathrm{T}_{\min }, \mathrm{DW}$ and WS) and the $\mathrm{PM} \mathrm{ET}_{\mathrm{o}}$ as a target. The optimum number of hidden neurons was finalized with a trial of 3-15 hidden nodes. For estimating $\mathrm{ET}_{\mathrm{o}}$ using $\mathrm{ANN}$ model, a network of single hidden layer with twelve numbers of hidden nodes was found as adequate. The results of ANN model showed better agreement of $\mathrm{R}=0.979, \mathrm{R}^{2}=0.957$ and RMSE $=0.44 \mathrm{~mm} /$ day with the PM method. This present study has demonstrated the potential of using the neural network with limited climatic data for 
reliable reference evapotranspiration. However, it should be noted that only climate data from agro ecological region of Egypt was used in this analysis and the results might be different for various climates in other countries.

\section{REFERENCES}

Ahmed, Kh. A.M.; Hegazi, M.M.; Abde-Aziz, A.A. and Kabeel, M.H. 2005. Comparison of artificial neural networks and analytical solution techniques in predicting the performance of gated pipe irrigation system. Role and horizons of Agricultural Engineering in the contemporary world. The 13 th Conference of the Misr Society of Agr. Eng., 14-15 December 2005: 207-222.

Allen, R.G.; Pereira, L.S.; Raes, D. and Smith, M.1998. Crop evapotranspiration - Guidelines for computing crop water requirements. Irrig. Drain. Paper 56, Food and Agriculture Organization of the United Nations (FAO), Rome, Italy, pp333.

Allen, R.G. ; Walter, I.A. ; Elliott, R. ; Mecham, B.; Jensen, M.E. ; Itenfisu , D. ; Howell, T.A. ;Snyder, R. ;Brown, P. ; Echings, S. ; Spofford, T. ; Hattendorf, M. ; Cuenca, R.H. ; Wright, J.L. and Martin, D.2000. Issues, requirements and challenges in selecting and specifying a standardized ET equation. In: Proc., 4th National Irri. Symp., Am. Soc. Agric. Eng. (ASAE), St. Joseph, Michigan, USA, pp8.

Banihabib, ME.; Valipour, M. and Behbahani, SMR.2012. Comparison of autoregressive static and artificial dynamic neural network for the forecasting of monthly inflow of Dez reservoir. J Environ Sci Technol 13(4):1-14.

Coulibaly, P.; Anctil, F. and Bobee, B. 2000. Daily reservoir inflow using artificial neural networks with stopped training approach. J Hydrol 230(3-4):244-257.

Eslamian, SS.; Abedi-Koupai, J.; Amiri, MJ. and Gohari, SA. 2009. Estimation of daily reference evapotranspiration using support vector machines and artificial neural networks in Greenhouse. Res J Environ Sci 3:439-447.

Gavilan, P.; Lorite, IJ.; Tornero, S. and Berengena, J.2006. Regional calibration of Hargreaves equation for estimating reference ET in a semiarid environment. Agric Water Manage 81:257-281.

Hargreaves, G.H. and Allen, R.G .2003. History and evaluation of Hargreaves evapotranspiration equation. J. Irrig. Drain. Eng. 129, 53-63.

Irmak, S.; Allen, RG. and Whitty, EB .2003.Daily grass and alfalfa 
reference evapotranspiration estimates and alfalfa-to-grass evapotranspiration ratios in Florida. J Irrig Drain Eng 129(5):360370.

Itenfisu, D.; Elliott, R.L.; Allen, R.G. and Walter, I.A .2003. Comparison of reference evapotranspiration calculations as part of the ASCE standardization effort. J. Irrig. Drain. Eng. 129 (6), 440-448.

Jadeja, V.2011. Artificial neural network estimation of Reference Evapotranspiration from pan evaporation in a semiarid environment. National Conference on Recent Trends in Engineering \& Technology, pp4.

Jones, JW.; Keating, BA. and Porter, CH.2001.Approaches to modular model development. Agr. Syst. 70:421-443.

Keskin, M.E. and Terzi, O.2006. Artificial neural network models of daily pan evaporation, Journal of Hydrologic Engineering, 11, 65-70.

Khoob, A.R .2008. Artificial neural network estimation of reference evapotranspiration from pan evaporation in a semi-arid environment, Irrigation Science, 27, 35-39.

Kim, S. and Kim, H.S.2008. Neural networks and genetic algorithm approach for nonlinear evaporation and evapotranspiration modeling, Agricultural Water Management, 351, 299-317.

Kisi, O.2008. The potential of different ANN techniques in evapotranspiration modeling, Hydrological Processes, 22, 24492460.

Kumar, M.; Raghuwanshi, N.S.; Singh, R.; Wallender, W.W. and Pruitt, W.O. 2002.Estimating evapotranspiration using artificial neural network, Journal of Irrigation and Drainage Engineering, 128, 224 233.

Landeras, G.; Ortiz-Barredo, A. and Lopez, J.J.2009. Forecasting weekly evapotranspiration with ARIMA and artificial neural network models, Journal of Irrigation and Drainage Engineering, 135, 323334.

Lepez-Urrea, R.; Olalla, F.M.S.; Fabeiro, C. and Moratalla, A .2006. Testing evapotranspiration equations using lysimeter observations in a semiarid climate. Agric. Water Mgmt. 85 (1-2), 15-26.

Nandagiri, L. and Kovoor, G.M .2006. Performance evaluation of reference evapotranspiration equations across a range of Indian climates. J. Irrig. Drain. Eng. 132 (3),238-249.

Rosenberry, DO.; Winter, TC.; Buso, DC. and Likens, GE .2007. Comparison of 15 evaporation methods applie; d to a small mountain 
lake in the Northeastern USA. J. Hydrol 340:149-166.

Sudheer, K.P.; Gosain, A.K. and Ramasastri, K.S.2003. Estimating actual evapotranspiration from limited climatic data using neural computing technique, Journal of Irrigation and Drainage Engineering, 129, 214 218

Trajkovic, S .2005. Temperature-based approaches for estimating reference evapotranspiration, Journal of Irrigation and Drainage Engineering, 131, 316-323.

Trajkovic S .2007. Hargreaves versus Penman-Monteith under humid conditions, Journal of Irrigation and Drainage Engineering, 133, 3842.

Trajkovic, S.; Todorovic, B. and Stankovic M.2003. Forecasting of reference evapotranspiration by artificial neural networks, Journal of Irrigation and Drainage Engineering, 129, 454-457.

Temesgen, B.; Eching, S. Davidoff, B. and Frame, K. 2005. Comparison of some reference evapotranspiration equations for California. J. Irrig. Drain. Eng. 131 (1), 73-84.

Utset, A.; Farre, I. Martinez-Cob, A. and Cavero J. 2004. Comparing Penman- Monteith and Priestley-Taylor approaches as reference evapotranspiration inputs for modeling maize water use under Mediterranean conditions. Agri Water Manage 66(3):205-219.

Valipour, M. 2014. Pressure on renewable water resources by irrigation to 2060. Acta Adv Agr Sci 2(8):32-42.

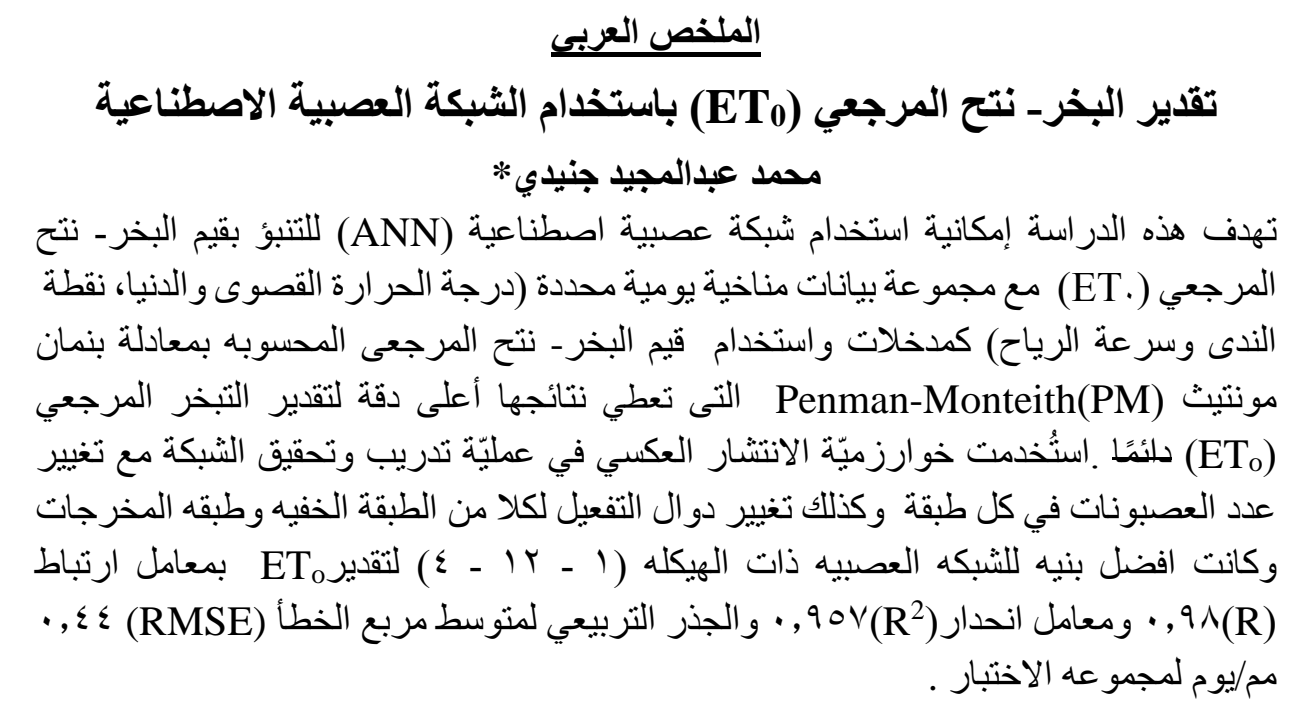

*قسم الهندسة الزراعيةـ كلية الزراعةـ جامعة عين شمس. 